\title{
Adult with Autistic Spectrum Disorders: Specialized Treatment
}

Fabienne Giuliani* and Pierre El Korh

Departement de Psychiatrie Prilly, Vaud, Switzerland

\begin{abstract}
Little is known in Switzerland regarding the profile of the adult population living with Asperger's Syndrome. This is why we conducted a descriptive study on a population in French-speaking Switzerland $(n=91)$ having received an Asperger's diagnosis as an adult and who were treated in a department of Psychiatry of Mental Development. The results of this study show that $68.5 \%$ of the men and $70.2 \%$ of the women are single. There were more married men $(22.2 \%)$ than women $(8.1 \%)$, however there were more divorced women $(21.6 \%)$ than men $(9.2 \%)$. We report that more men $(37 \%)$ than women $(18.9 \%)$ completed their mandatory schooling and more women $(62.2 \%)$ than men $(44.4 \%)$ completed post-mandatory schooling (apprenticeship or cantonal aptitude degree). In terms of those with a university degree, there was a parity between men and women (18\%). Half of our study sample was employed; the other half received a disability income. The Global Assessment of Functioning scale is estimated to be on average $68.9( \pm 12.87)$. This scale was correlated with civil status, level of education completed as well as professional situation.
\end{abstract}

Keywords: Descriptive study; The biopsychosocial situation; Adult with autistic spectrum disorders

\section{Introduction}

Autism spectrum disorders (ASD) are neuro-developmental disorders and affect men four times more than women. The prevalence is estimated at 1: 5000 in 1975, 1:2500 in 1985, 1: 500 in 1995, 1: 110 in $2009,1: 88$ in 2012 [1] and today it is estimated at 1:68 [2]. As explained by Hadjikhani [3], autism spectrum disorders are now more frequent than childhood cancers, juvenile diabetes and pediatric AIDS, and pose significant challenges for both public health and education. Individuals living with an ASD: 1) altered social communication, 2) restricted interests, repertories and behaviors.

With the American publication of the 5th edition of the DSM [4], the category of "Pervasive Developmental Disorders" (PDD) has become "Autism Spectrum Disorders" (ASD). Until now the group belonging to PDD contained five different diagnoses, but going forward all ASDs will be kept within a single diagnosis. This means that Asperger's Syndrome is no longer differentiated as a specific category of autism, it is now included beneath the larger designation of autism spectrum disorders without mental retardation whose symptoms lie on the same continuum. Various justifications led to this reunification: firstly, Asperger's Syndrome and high-functioning autism are fairly close. Essentially, the main difference resides in the absence of a language delay for individuals with Asperger's Syndrome as well as the absence of any criteria for another developmental disorder like schizophrenia. Because it wasn't possible to scientifically demonstrate this difference between the two diagnoses, it was decided that Asperger's be considered a sign of ASD.

"In this new version, the alteration of social interactions and communication are now gathered within the category "altered social communication." Sensitivity elements (hypo and hypersensitivity), noted in autism patients, are indicated under the B criteria (restricted, repetitive and stereotyped behaviors and activities). Finally, in terms of $\mathrm{A}$ and $\mathrm{B}$ criteria, clinicians are asked to evaluate the severity of the actual handicap according to the support the individual requires, something which is new.

This article presents the results of a descriptive study on a sample of adult patients at the Section de psychiatrie du Dévelopement Mental (SPDM; Department of Psychiatry of Mental Development) at the Centre Hospitalier Universitaire Vaudois (CHUV; Vaud University Hospital) in Switzerland.
This study began prior to the publication of the DSM-V, which is why we note the diagnostic change for Asperger's Syndrome. Our study is notable for being one of the first to describe the social and professional profiles of an adult population treated within a specialized Asperger's unit.

Very little is known about the social and health situation of this adult population $[5,6]$, and furthermore, there has not been a descriptive study of this population in Switzerland. Cantonal resources in adult psychiatry specializing in the area of autism spectrum disorders are low, which is why there is currently a discrepancy in terms of specific care measures. This is the result of a lack of equipment and specialized personnel in this area.

\section{Method}

When a patient was treated within our department and a medical file created we were able to receive a certain amount of clinical information. The patient gave consent for the use of her or her medical file - for research purposes. We compiled information from 91 adults. We used the Global Assessment of Functioning scale from the DSM-IV [7] (GAF) in order to evaluate the psychological, social and professional functioning along a hypothetical continuum from mental health to mental illness. We also took age, gender, civil status, education level and professional activity into consideration, as well as the age at which the individual was first diagnosed. The Asperger's Syndrome diagnosis of these patients corresponded to the diagnostic criteria of the DSM-IV. Furthermore, the individuals in our sample did not have any psychiatric comorbidity.

Repeated variance analyses (ANOVA) were conducted in order to compare the results obtained between the GAF, gender, civil status, education level and professional activity. Fisher's post-hoc and other simple correlation comparisons were performed.

*Corresponding author: Fabienne Giuliani, Departement de Psychiatrie Prilly, Vaud, Switzerland, Tel: 41213142185; E-mail: Fabienne.giuliani@chuv.ch

Received January 19, 2016; Accepted January 29, 2016; Published February 05, 2016

Citation: Giuliani F, El Korh P (2016) Adult with Autistic Spectrum Disorders: Specialized Treatment. Adv Tech Biol Med 4: 164. doi: 10.4172/2379-1764.1000164

Copyright: ( 2016 Giuliani F, et al. This is an open-access article distributed under the terms of the Creative Commons Attribution License, which permits unrestricted use, distribution, and reproduction in any medium, provided the original author and source are credited. 
Citation: Giuliani F, El Korh P (2016) Adult with Autistic Spectrum Disorders: Specialized Treatment. Adv Tech Biol Med 4: 164. doi: 10.4172/23791764.1000164

Page 2 of 5

\section{Results}

Of the 91 adults studied, there were 54 men and 37 women. The number of women treated in our department $(40.7 \%)$ was higher than what is found in the literalture. This higher percentage of women could indicate that once diagnosed, women with Asperger's might be in a situation of stronger psychological suffering, motivating a request for care. Average age was 34 years (standard deviation of \pm 12.2 years, divided between 18 and 73 years). The average age the patient was first diagnosed was 34.05 (standard devitation of \pm 10.12 years divided between 19 and 73 years).

Results are presented in Table 1.

\begin{tabular}{|c|c|c|c|c|}
\hline Population=91 & Men & Women & $\%$ Men & \% Women \\
\hline Number age class: & 54.0 & 37.0 & 59.3 & 40.7 \\
\hline$<21$ & 2 & 2 & 3.7 & 5.4 \\
\hline$<21 ; 30>$ & 21 & 10 & 38.9 & 27.0 \\
\hline$<31 ; 40>$ & 11 & 15 & 20.4 & 40.5 \\
\hline$<41 ; 50>$ & 10 & 7 & 18.5 & 18.9 \\
\hline$<51: 60>$ & 8 & 2 & 14.8 & 5.4 \\
\hline$<61 ; 70>$ & 1 & 1 & 1.9 & 2.7 \\
\hline$<71 ; 80>$ & 1 & 0 & 1.9 & 0.0 \\
\hline \multicolumn{5}{|l|}{ Civil status: } \\
\hline Single & 37.0 & 26.0 & 68.5 & 70.3 \\
\hline$<21$ & 2.0 & 2.0 & 5.4 & 7.7 \\
\hline$<21 ; 30>$ & 21.0 & 9.0 & 56.8 & 34.6 \\
\hline$<31 ; 40>$ & 8.0 & 4.0 & 21.6 & 15.4 \\
\hline$<41 ; 50>$ & 5.0 & 8.0 & 13.5 & 30.8 \\
\hline$<51: 60>$ & 0.0 & 2.0 & 0.0 & 7.7 \\
\hline$<61 ; 70>$ & 1.0 & 1.0 & 2.7 & 3.8 \\
\hline$<71 ; 80>$ & - & - & - & - \\
\hline Married & 12.0 & 3.0 & 22.2 & 8.1 \\
\hline$<21$ & - & - & - & - \\
\hline$<21 ; 30>$ & - & - & - & - \\
\hline$<31 ; 40>$ & 2.0 & 1.0 & 16.7 & 33.3 \\
\hline$<41 ; 50>$ & 2.0 & 2.0 & 16.7 & 66.7 \\
\hline$<51: 60>$ & 6.0 & - & 50.0 & - \\
\hline$<61 ; 70>$ & 1.0 & - & 8.3 & - \\
\hline$<71 ; 80>$ & 1.0 & - & 8.3 & - \\
\hline Divorced & 5.0 & 8.0 & 9.3 & 21.6 \\
\hline$<21$ & & - & & - \\
\hline$<21 ; 30>$ & - & 1.0 & & 12.5 \\
\hline$<31 ; 40>$ & 1.0 & 2.0 & 20.0 & 25.0 \\
\hline$<41 ; 50>$ & 3.0 & 5.0 & 60.0 & 62.5 \\
\hline$<51: 60>$ & 1.0 & - & 20.0 & - \\
\hline$<61 ; 70>$ & - & - & - & - \\
\hline$<71 ; 80>$ & - & - & - & - \\
\hline \multicolumn{5}{|c|}{ Education level achieved: } \\
\hline Mandatory schooling & 20.0 & 7.0 & 37.0 & 18.9 \\
\hline$<21$ & 2.0 & - & 10.0 & - \\
\hline$<21 ; 30>$ & 11.0 & 2.0 & 55.0 & 28.6 \\
\hline$<31 ; 40>$ & 4.0 & 1.0 & 20.0 & 14.3 \\
\hline$<41 ; 50>$ & 2.0 & 4.0 & 10.0 & 57.1 \\
\hline$<51: 60>$ & 1.0 & - & 5.0 & - \\
\hline$<61 ; 70>$ & - & - & - & - \\
\hline$<71 ; 80>$ & - & - & - & - \\
\hline $\begin{array}{l}\text { Post-mandatory } \\
\text { schooling }\end{array}$ & 24.0 & 23.0 & 44.4 & 62.2 \\
\hline$<21$ & - & 1.0 & - & 4.3 \\
\hline
\end{tabular}

\begin{tabular}{|c|c|c|c|c|}
\hline$<21 ; 30\rangle$ & 7.0 & 6.0 & 29.2 & 26.1 \\
\hline$<31 ; 40\rangle$ & 5.0 & 4.0 & 20.8 & 17.4 \\
\hline$<41 ; 50>$ & 6.0 & 9.0 & 25.0 & 39.1 \\
\hline$<51: 60>$ & 5.0 & 2.0 & 20.8 & 8.7 \\
\hline$\langle 61 ; 70\rangle$ & 1.0 & 1.0 & 4.2 & 4.3 \\
\hline$<71 ; 80>$ & - & - & - & - \\
\hline University & 10.0 & 7.0 & 18.5 & 18.9 \\
\hline$<21$ & & 1.0 & - & 14.3 \\
\hline$<21 ; 30>$ & 3.0 & 2.0 & 30.0 & 28.6 \\
\hline$<31 ; 40>$ & 2.0 & 2.0 & 20.0 & 28.6 \\
\hline$\langle 41 ; 50\rangle$ & 2.0 & 2.0 & 20.0 & 28.6 \\
\hline$<51: 60>$ & 2.0 & - & 20.0 & - \\
\hline$\langle 61 ; 70\rangle$ & & - & - & - \\
\hline$\langle 71 ; 80\rangle$ & 1.0 & - & 10.0 & - \\
\hline \multicolumn{5}{|l|}{ Professional Activity: } \\
\hline employed & 27.0 & 19.0 & 50.0 & 51.4 \\
\hline$<21$ & - & 1.0 & - & 5.3 \\
\hline$<21 ; 30>$ & 12.0 & 7.0 & 44.4 & 36.8 \\
\hline$<31 ; 40>$ & 6.0 & 4.0 & 22.2 & 21.1 \\
\hline$\langle 41 ; 50\rangle$ & 3.0 & 5.0 & 11.1 & 26.3 \\
\hline$<51: 60>$ & 4.0 & 1.0 & 14.8 & 5.3 \\
\hline$<61 ; 70>$ & 1.0 & 1.0 & 3.7 & 5.3 \\
\hline$<71 ; 80\rangle$ & 1.0 & - & 3.7 & - \\
\hline $\begin{array}{l}\text { Unemployed (disability } \\
\text { income) }\end{array}$ & 27.0 & 18.0 & 50.0 & 48.6 \\
\hline$<21$ & 2.0 & 1.0 & 7.4 & 5.6 \\
\hline$<21 ; 30>$ & 9.0 & 3.0 & 33.3 & 16.7 \\
\hline$<31 ; 40>$ & 6.0 & 3.0 & 22.2 & 16.7 \\
\hline$<41 ; 50\rangle$ & 6.0 & 10.0 & 22.2 & 55.6 \\
\hline$<51: 60>$ & 4.0 & 1.0 & 14.8 & 5.6 \\
\hline$\langle 61 ; 70\rangle$ & - & - & - & - \\
\hline$<71 ; 80>$ & - & - & - & - \\
\hline GAF: & 67.8 & 70.0 & & \\
\hline Standard deviation & 1.9 & 2.2 & & \\
\hline$<21$ & 55.0 & 70.0 & & \\
\hline$<21 ; 30>$ & 65.5 & 75.0 & & \\
\hline$<31 ; 40>$ & 72.7 & 70.0 & & \\
\hline$<41 ; 50>$ & 68.3 & 66.0 & & \\
\hline$<51: 60>$ & 67.5 & 55.0 & & \\
\hline$<61 ; 70>$ & 80.0 & 61.0 & & \\
\hline$<71 ; 80>$ & 80.0 & - & & \\
\hline Age at time of diagnosis & 33.9 & 34.2 & & \\
\hline Standard deviation & 1.7 & 1.8 & & \\
\hline
\end{tabular}

Table 1: Psychological, social and professional situation of the adult ASD population.

\section{Civil status}

We report that a great proportion of these adults are single: $68.5 \%$ of the men and $70.3 \%$ of the women. There were more married men $(22.2 \%)$ than women $(8.1 \%)$, however there was an opposite tendency for those who were divorced; there were more divorced women $(21.6 \%)$ and they fell between the ages of 21 and 50 years old. There were fewer divorced men $(9.3 \%)$ and they fell between the ages of 31 and 60 years old.

\section{Education level}

The Swiss school system comprises the following educational levels: compulsory education until the age of 15 years. Beyond this age, we speak of (it is known as) post-compulsory education. This 
Citation: Giuliani F, El Korh P (2016) Adult with Autistic Spectrum Disorders: Specialized Treatment. Adv Tech Biol Med 4: 164. doi: 10.4172/23791764.1000164

corresponds to the diploma obtained after compulsory education. We report that in our sample there were more men (37\%) than women (18.9\%) who had finished mandatory schooling. 55\% of the men who had completed mandatory schooling were between 21 and 30 years old, while $57 \%$ of the women with the same were between 41 and 50 years old. The majority of the women $(62.2 \%)$, however, had completed postmandatory schooling, meaning that they had a Swiss Federal Certificate of Capacity or a Cantonal degree. Our sample mostly included women between 21 and 30 years old and 41 and 50 years old. For the men, our results found that only $44.4 \%$ of the men had completed postmandatory schooling. The number of men with this education level only slightly varied between 21 and 50 years old. In terms of those with a university degree, there was a parity between men and women of $18 \%$.

\section{Professional activity}

Concerning the professional activity of the sample, we found a virtual parity between the men and the women. Half of our study sample was employed, most of these being young adults between the ages of 21 and 30; the other half received a disability income. For those who receive disability income, there is a distinct difference between the men and the women. The men fall between 21 and 50 years old while the majority of the women are between 41 and 50 years old (Table 1).

\section{The global assessment of functioning scale (GAF)}

The Global Assessment of Functioning scale shows that individuals with Asperger's fall between 50 (serious symptoms with serious impairment of social and professional functioning) and 80 (mild symptoms with some difficulty in social and professional functioning). ANOVA repeated variance analyses of GAF results on gender and civil status showed a significant difference between men and women ( $\mathrm{F}(1$, 91) $=12.356, p=0.0008)$ as well as a significant difference in civil status (F $(2,91)=27.629, p<0.0001)$ but no interaction between gender and civil status. As shown in Figure 1, divorced individuals with Asperger's have a significantly lower GAF compared to those who are married $(p<0.0001)$ and those who are single $(p<0.0001)$. There does not appear to be any significant difference between individuals who are single and those who are married $(p=0.0599)$ (Figure 1$)$

ANOVA repeated variance analyses of GAF on gender and professional activity show a significant difference in professional situation $(F(1,91)=120.371, p<0.0001)$ but no difference in terms of men/women nor in terms of an interaction between gender and professional situation. As shown in Figure 2, individuals with Asperger's

Comparison of GAF as a function of civil status

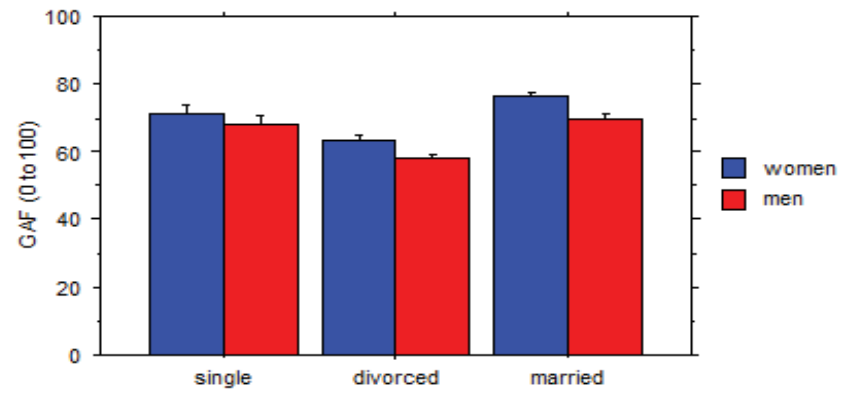

Figure 1: Comparison of GAF as a function of civil status. Divorced individuals with Asperger's have a significantly lower GAF compared to those who are married $(p<0.0001)$ and those who are single $(p<0.0001)$. There does not appear to be any significant difference between individuals who are single and those who are married $(p=0.0599)$.
Comparison of GAF as a function of professional activity

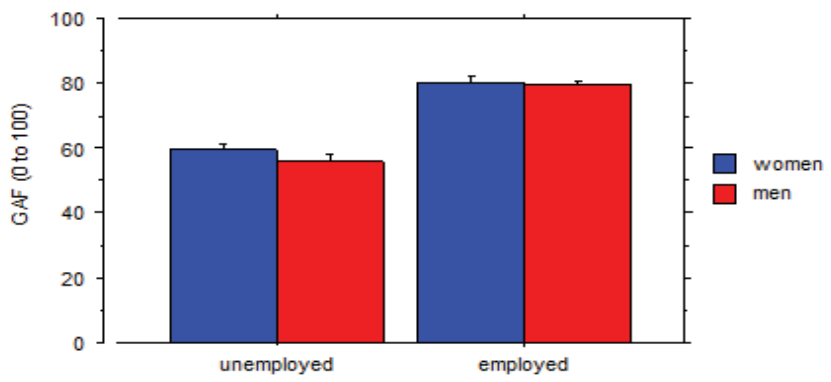

Figure 2: Comparison of GAF as a function of professional activity. Individuals with Asperger's who are employed have a higher functioning scale compared to those who receive disability income.

Comparison of GAF as a function of education level completed

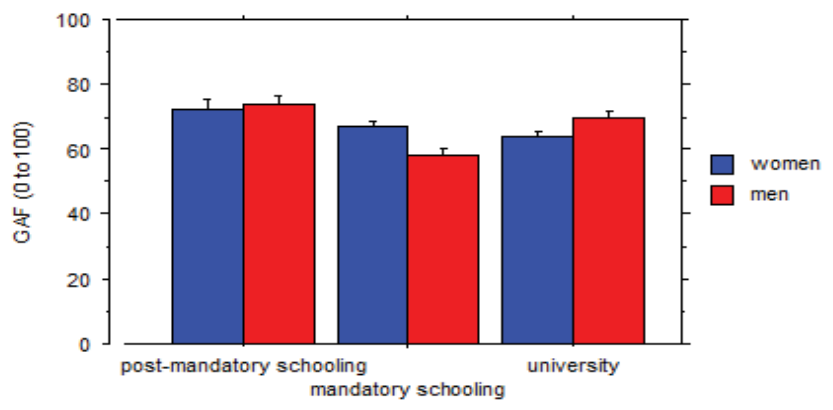

Figure 3: Comparison of GAF as a function of education level completed. Individuals with Asperger's who completed a post-mandatory educational level (high school or apprenticeship) have a higher functioning scale compared to those who completed only mandatory schooling $(p<0.0001)$ and those with a university degree $(p=0.0015)$. Those with a university degree also have a higher functioning scale compared to those who completed their mandatory schooling $(p=0.0114)$.

who are employed have a higher functioning scale compared to those who receive disability income (Figure 2).

ANOVA repeated variance analyses of the GAF on gender and educational level shows a significant difference in level of study completed $(\mathrm{F}(2,91)=16.899, p<0.0001)$ but no difference between men and women; there appears to be an interaction between gender and educational level $(\mathrm{F}(2,182)=8.57, p=0.0004)$. Post-hoc Fisher tests showed significant differences in all three levels, meaning completion of mandatory schooling, post-mandatory schooling and university degree. As shown in Figure 3, individuals with Asperger's who completed a post-mandatory educational level (high school or apprenticeship) have a higher functioning scale compared to those who completed only mandatory schooling $(p<0.0001)$ and those with a university degree $(p=0.0015)$. Those with a university degree also have a higher functioning scale compared to those who completed their mandatory schooling $(p=0.0114)$ (Figure 3).

The Spearman correlation conducted between the age at diagnosis and the GAF did not show a significant effect of age on GAF.

\section{Discussion}

This study was the first conducted in Switzerland on this adult population undergoing specialized care in a university hospital department (CHUV). There are very few studies which describe 
the health status and social situation of adults living with Asperger's Syndrome $[6,8]$, which is why our study responds to several unknowns amidst our current knowledge of the social and economic situation of individuals with Asperger's. Several elements of our results should be highlighted. In our study, only $16.4 \%$ of the individuals with Asperger's were married (genders combined) and there was a distinct difference between men/women. Indeed, the percentage of married men was significantly higher than married women. At the same time, there were a higher percentage of divorced women in the study compared to divorced men. Finally, the number of single men and women patients was equal. This difference in civil status is interesting, although the small size of our sample ( $\mathrm{n}=91$ individuals) must be considered. At this stage we can cautiously formulate several explanations:

On the one hand, we underscore the fact that sense perception is highly individualized; individuals with Asperger's (men or women) who suffer from severe sensory hypersensitivity may be particularly blocked in terms of their first contact with a partner. This idea is broadly discussed by Attwood [9]: "tactile sensitivity can also affect sensual and sexual relationships between an Asperger's adult and his or her partner". The author specifies (p. 335-336) that: "gestures of daily affection like 'touching a forearm to reassure the other person, or to show affection and love by kissing, may not be perceived as pleasant sensations for an individual with Asperger's syndrome. A spouse or partner may be unhappy at the absence of pleasure these gestures provide, and regret the scarcity of such gestures from a partner". Hénault [10] reminds that: "all five senses are an integral part of one's sexuality and this indicates that because of an Asperger's patient's extreme sensory sensitivity, he or she may not enjoy intimate contact: s/he may find these experiences to be unpleasant, even difficult to tolerate, and even less so a pleasurable experience. This aversion to physical contact during moments of sexual intimacy may originate more from a problem of sensory perception rather than a lack of love or engagement in the relationship".

On the other hand, as Ney mentioned in his thesis [11]: "according to Attwood [9], the social immaturity and naivety of a woman with Asperger's may be attractive to men who have paternal and compassionate feelings. And sometimes there may be an evident physical attraction, as well as talent and admirably capacities. Her sometimes emotionally distant personality may evoke, for the man, his mother, and there may be mutual pleasure in shared interests and the joy of first passion".

Ultimately, we can report that the small sample of individuals living as a couple who came for treatment in our department had a higher GAF score compared to those who were single or divorced. Since our study is purely descriptive and non-sociological, we can imagine this to be a normal tendency given that in the general population, surveys indicate a better overall functioning among married couples compared to singles. A comparative study would be needed to specify the mode of functioning in Asperger's couples.

The data we obtained are both descriptive and small scale. They show that individuals who receive a disability income have a tendency to score lower on the GAF. On the other hand, our data show that Asperger's patients who have completed post-mandatory schooling seem to have a higher psychological, social, and professional functioning compared to those who completed their mandatory schooling only or a university degree. This result brought us to reflect upon the fact that individuals with Asperger's who have gone on to pursue university studies seem to have some difficulties meeting their professional expectations, once they've completed their studies, while the individual with a Swiss Certificate of Federal Aptitude (CFC) seems better able to maintain a job. A comparative study would make it possible to specify the expectations and difficulties encountered in the work place by individuals with Asperger's.

Our results echo those of previous studies [6,12-16] which have demonstrated the social challenges encountered by adults living with Asperger's Syndrome such as social and professional isolation, and limitations in terms of the possibilities of completing a university degree. Other studies have highlighted the fact that this population needs support in order to live autonomously $[6,17,18]$ and even if our study was both descriptive and uncontrolled, our results concerning those individuals receiving disability income seem to agree.

The professional situation of individuals living with Asperger's syndrome in French-speaking Switzerland appears to be favorable for employment compared to other studies. Indeed, in our description, half of our sample was gainfully employed, while the study by Balfe and Tantam [6] reported only $21 \%$ and the study by Barnard et al. [19], reported only $12 \%$.

\section{Conclusion}

In our example, the appearance of psychiatric resources specializing in autism spectrum disorders in adults five years ago prompted a paradigm change in the field of ASD, leading to improvements in diagnostic tools and therapeutic resources. This change made it possible to improve the daily life conditions of individuals with Asperger's Syndrome, notably through continued employment or an autonomous life at home.

With this study, we have looked to evaluate this paradigm change by focalizing on the social and professional functioning of a population of adult subjects who were treated at a department specializing in Asperger's.

A strong point of this study is that it is one of the first to describe the characteristics of this population in Switzerland using data from patient files at a university hospital. Our study made it possible to put forward questions concerning the social adaptation of these individuals and opened up a line of thought about the specific needs they may have in terms of their handicap and, eventually an improvement in their quality of life.

We noted that in our sample, the ASD adults who were treated in our department all received their diagnosis quite late (average age of 34 years). This issue has already been discussed by Grasset et al. [20] who insists upon finding the resources to develop a specialized psychiatry in the area of adult ASD evaluations and consultations, by offering a scientific and holistic approach for ASD individuals and by integrating the collaboration of families, associations and different professions.

\section{References}

1. Baio J (2008) Prevalence of Autism Spectrum Disorders.

2. Developmental Disabilities Monitoring Network Surveillance Year 2010 Principal Investigators; Centers for Disease Control and Prevention (CDC) (2014) Prevalence of autism spectrum disorder among children aged 8 years - autism and developmental disabilities monitoring network, 11 sites, United States, 2010. MMWR Surveill Summ 63: 1-21.

3. Hadjikhani N (2014) Scientifically deconstructing some of the myths regarding autism. Swiss archives of neurology and psychiatry 165: 272-276.

4. DSM-V (2013) Diagnostic and Statistical Manual of Mental Disorders. American Psychiatric Association, Washington, DC.

5. Tantem D (2000) Psychological Disorder in Adolescents and Adults with Asperger Syndrome. Autism 4: 47-62.

6. Balfe M, Tantam D (2010) A descriptive social and health profile of a community 
Citation: Giuliani F, El Korh P (2016) Adult with Autistic Spectrum Disorders: Specialized Treatment. Adv Tech Biol Med 4: 164. doi: 10.4172/23791764.1000164

Page 5 of 5

sample of adults and adolescents with Asperger syndrome. BMC Res Notes 3: 300 .

7. DSM-IV (2000) diagnostic and statistical manual of mental disorders. American Psychiatric Association, Washington, DC.

8. Barnhill GP (2007) Outcomes in adults with Asperger syndrome. Focus on Autism and other Developmental Disabilities 22: 116-126.

9. Attwood T (2011) Le syndrome d'Asperger - guide complet. Bruxelles: De Boeck, Belgium.

10. Hénault I (2010) Sexualité et syndrome d'Asperger: éducation sexuelle et intervention auprès de la personne autiste. Bruxelles: De Boeck, Belgium.

11. Ney C (2014) Comment se construit la vie de couple lorsque l'un des partenaires est atteint du syndrome d'Asperger? Ecole d'études sociales et pédagogique: Lausanne 167

12. Sperry LA, Mesibov GB (2005) Perceptions of social challenges of adults with autism spectrum disorder. Autism 9: 362-376.

13. Humphrey N, Lewis S (2008) 'Make me normal': the views and experiences of pupils on the autistic spectrum in mainstream secondary schools. Autism 12 23-46.
14. Müller E, Schuler A, Yates GB (2008) Social challenges and supports from the perspective of individuals with Asperger syndrome and other autism spectrum disabilities. Autism 12: 173-190.

15. Madriaga M (2010) I avoid pubs and the student union like the plague: Students with Asperger syndrome and their negotiation of university spaces. Children's Geographies 8: 23-34.

16. Jennifer JW, Paul N, Paul S, Digby T, Jenna VW (2008) Relationships with peers and use of the school environment of mainstream secondary schoo pupils with Asperger syndrome (High-Fuctioning Autism): A case-control Study. International Journal of Psychology and Psychological Therapy 38: 72-85.

17. Portway S (2000) The Needs of Children and Adults Living with Asperger syndrome in Berkshire. Berkshire Autistic Society, London.

18. Eaves LC, Ho HH (2008) Young adult outcome of autism spectrum disorders. J Autism Dev Disord 38: 739-747.

19. Judith B, Virginia H, Aidan P, David P (2001) Ignored or Ineligible? The Reality for Adults with Autistic Spectrum Disorders. National Autistic Society, London.

20. Grasset F, Favrod J, Giuliani F, Pernier S, Navarro Chafloque M, et al. (2008) [Mental retardation and psychiatry]. Rev Med Suisse 4: 1976-1978, 1980-1981.
Citation: Giuliani F, El Korh P (2016) Adult with Autistic Spectrum Disorders: Specialized Treatment. Adv Tech Biol Med 4: 164 doi: 10.4172/23791764.1000164

\section{OMICS International: Publication Benefits \& Features}

\section{Unique features:}

- Increased global visibility of articles through worldwide distribution and indexing

Showcasing recent research output in a timely and updated manner

Special issues on the current trends of scientific research

Special features:

700 Open Access Journals

50,000 editorial team

Rapid review process

Quality and quick editorial, review and publication processing

Indexing at PubMed (partial), Scopus, EBSCO, Index Copernicus and Google Scholar etc

Sharing Option: Social Networking Enabled

Authors, Reviewers and Editors rewarded with online Scientific Credits

- Better discount for your subsequent articles

Submit your manuscript at: http://www.omicsonline.org/submission/ 